\title{
Education for the Creative Cities: Awareness Raising on Urban Challenges and Biocultural Preservation
}

\author{
Aida Mammadova ${ }^{1}$ \\ ${ }^{1}$ International Student Center, Kanazawa University, Ishikawa, Japan \\ Correspondence: Aida Mammadova, International Student Center, Kanazawa University, Ishikawa, Japan. \\ E-mail: mammadova@staff.kanazawa-u.ac.jp
}

Received: November 9, 2017

Accepted: November 30, 2017 Online Published: December 21, 2017

doi:10.5539/jel.v7n2p60

URL: http://doi.org/10.5539/jel.v7n2p60

\begin{abstract}
Creative Cities are facing the big challenges due to the demographical, environmental and economic issues. In this study we considered to create the educational fieldworks inside the creative city and raise the awareness in youth about the importance of the biocultural preservations to sustain the city's creativity and sustainability. Our participants were 10 international participants with different backgrounds and majors. The fieldwork trips were divided according to the ecosystems of Kanazawa City, in three main part: mountain areas, rives and forest areas and finally coastal areas. In each course students directly interviewed the local artists, craftsmen and shop owners and recorded about the importance of biocultural diversity to preserve the city's traditions. Evaluation of the students were conducted according to the submitted reports with comparative analysis, and providing further recommendations. From the results, awareness level about the present issues was increased in each student, and they provided the recommendation according to the local issues. However, this time we did not considered the scientific background of all interviews, and all recommendations were given based on the opinions of the locals. To improve our methodological approach in our next studies we are going to develop approved survey instruments to record and analyse the data collected by students, and perform quantitative data analysis with second cohort research group to evaluate and confirm the outcomes of the field trips.
\end{abstract}

Keywords: biocultural diversity, sustainability, creativity, fieldworks, awareness raising

\section{Introduction}

\subsection{Creative Cities and Biocultural Diversity}

The concept of the creative cities have been developed as a new paradigm for the cities to boost the urban economy, through fostering the creativity and cultural industries while sustaining the emotional satisfaction among the citizens. Creative cities requires three main factors to increase the urban economy, as it is described by Hospers (Hospers, 2013): 1). Concentration of the creative number of people for the sufficient communication and interaction. 2). Diversity of the skills, knowledge as well as surrounding environmental conditions. 3). Instability as the trigger to boost creativity. Creative culture is derived from the utilization of the diverse natural resources, and the biologically diverse environment are embodied in people's creativity skills and talents. Later, those skills accumulated for the creation of the cultural resources and cultural diversity, and represented in the forms of Things like crafts, local products, values, believes, languages, architectures, urban landscapes and creative industries. Creating culture is strongly related with the natural environment and provided ecosystem services. This kind of strong and "inextricable linkage" between cultural and natural diversity was recognized in 1988 in the Declaration of Belem of the International Society of Ethnobiology (Declaration of Belem, 1988). Later this linkage were investigated by different scientific fields, like natural, social, behavioral and other sciences, resulting in creating a new concept as "biocultural diversity" (Maffi, 2007). Since the origin on the concept, many researches were mainly conducted focusing on investigating the biocultural relationships in the rural areas, as they have still preserved the strong connections between nature and culture. Researches were conducted in biocultural measurements methods, biocultural loss and preservations, language and its relation to biodiversity. However, less is known about the biodiversity and cultural diversity of the urban areas, which regulates the economy and the society of the city in sustainable manner. It is well known that most of the ecosystems of the creative cities are obtained from the rural areas, and it will be crucial to consider both areas, for the sustainable development. 


\subsection{Issues of the Creative Cities}

Urban areas are facing major challenges such as demographic growth, environmental changes, economic crisis, and social issue that prevents sustainable development. Due to the fast industrialization, humanities are rapidly urbanizing, and it is estimated that by 2030 more than $60 \%$ of the world population will be living in the cities (UN, 1997). The concept of biocultural diversity and awareness for wellbeing and sustainability has yet to be centralized in the urban context for the rural migrants (WinklerPrins \& De Souza, 2005). It is important to pay biggest attention to the linkage between the natural resources and urban culture which provides the sustainable local production-consumption patterns, and increase economic opportunities for the regional development as well.

One of the main issues that impede sustainable urban development is the lack of the awareness about the relationship between environmental issues with the loss of cultural resources, especially in young generations.

\subsection{Educational Approach to Raise the Awareness in Urban Issues and Objective of the Study}

Education is considered to be crucial to raise the awareness among the youth toward the sustainable development and educate the sense of oneness between the environmental sustainability and cultural creativity (Prokop et al., 2007; Ramadoss \& Poyyamoli, 2011; Hafezi et al., 2013). Many studies have already shown the effectiveness of fieldworks activities to raise the awareness on environmental issue (Özden, 2008; Hungerford \& Volk, 1990), however, until now there were no studies that gave the students the opportunity to experience the cultural "interlinkage" with nature and environment. One of the teaching approaches in the education for the environmental sustainability and creativity is the education through the fieldworks, which provide the opportunities for the students, to experience local culture, nature and directly learn from the local people.

In our approach to increase the awareness about urban biocultural challenges, we used fieldwork activities, whereby students were able to directly learn about the culture and the creativity of the local people as well as engage with the issues that they face. In this study our main goal was to introduce the newly established fieldtrips program by linking cultural experience together with nature, and discuss on the challenges and further improvements of the teaching methodology.

Kanazawa City was chosen as the destination for our fieldtrips, due to the rich culture of the city which is inextricably linked with the diverse ecosystems. The city develops its economy with the preservation of its environment and ecosystem services, thereby creating a balance in its economy between traditional and modern culture, and displays the strong traditional cultural identity of the local people (Sasaki, 2003). The City's economy avoids large-scale industrial development, and protects its traditional industries, cityscapes and natural environment, by running a group of sustainable medium and small-sized companies, with many cultural investments. The city's population is almost half a million people, and the locals for many years cultivated the ability to maintain a lifestyle in harmony with the traditional cityscape and crafts, and it is not surprising that in 2009 the city was designated as a UNESCO Creative City in the field of crafts (Kanazawa UNESCO Creative City, 2016). Kanazawa City is second city only to Kyoto, in terms of preserving the traditional crafts with 26 verified industries. "Co-existence with nature" is the main goal of the local government policy making and implementation. Conservation, revitalization and creation of natural environment in the urban area is a main principle of urban planning and development of the city. After the year of fast economic growth, the city developed the policies for the preservation of the traditional environment and the creation of scenic landscapes, conservation of green areas and water environments, conservation of canals, green slopes and promotion of green city buildings. Later in 2003, the city established policies for the Forest Development, and established the Kanazawa City College of Forestry to develop human resources for forestry management. All these policy measures undertaken by the local government had significant impacts in terms of the conservation of natural habitats in the city (Biodiversity strategy of Kanazawa City, 2017). Besides, the biocultural concepts are strongly manifested in the strategical plans for the city's development and implemented in the local policies of different economic sectors; such as traditional crafts preservation, local cuisine, agriculture sectors and traditional architectural cityscapes preservations.

\section{Method}

In 2016 from October to January, we conducted an academic course towards the "Biocultural diversity of Creative City Kanazawa" to the international students from Kanazawa University. The aim of this course was to find the linkage between biological and cultural diversity though fieldwork, while also raising the awareness about the importance of sustainable environmental utilization for the city's creative cultural development. Participants were 15 international students with different backgrounds. 


\subsection{Fieldworks Design}

Fieldwork was divided into three main courses due to the diverse natural environment of the city, such as mountain, river and coastal courses. Mountain regions, were aimed to observe the traditional ways of utilization on natural resources in the rural areas. Visited destinations were stone-pottery making atelier, Japanese traditional paper making atelier, local farmer's house, traditional restaurant which breeds the rock-fish and local café in the mountain area which provide the food made only from local vegetables. River sides course provide the students the opportunity to learn about the Biocultural Diversity within the city, with lots of historical shops and cultural attraction places along the Asano-river, which flows inside the city's historical center. Places like making fishing flies Kaga-kebari atelier, rice-candy Tawara-ya candy shop, food preservation Tsukudani-shop, wooden souvenir shop Asunaro, green tea shop Yonezawa, rice celling shop for more than 100 years shop Kyoden, local park with many temples and shrines Utatsuyama park were visited. Coastal course was aimed to show the biocultural diversity of the coastal region and its relation with local food production and traditional architecture. Course started by visiting the local shrine in Ono town Hiyoshi Shrine, one of the oldest soy sauce making factory Naogen soy souce shop and relatively new Moromi-gura shop, Yamato Soysauce and Miso Shop. Later visited the Kanazawa Port by small ship and visited the Kahoku Lagoon, as filled land to promote the local farming and agricultural sectors of the city.

\subsection{Research Design and Evaluation}

During each course, students where provided with the map with the marked destinations, and were asked to visit each destination and learn directly about traditional culture and nature of the locals. They conducted the interviews to the local people and recorded their daily activities. After each course, students submitted reports in which they described the following 1). Opportunities that increase the creativity in local communities and how it relates with the natural environment. By understanding the strong linkage between the biological and cultural diversity and the value of the nature, students could learn how the loss of one of those diversities, can cause the chain reaction and lead to the loss of others (Udy, 1973). 2). Present issues of the region, which impede the creativity. 3). Make comparative analysis of biocultural diversity of the region with their own home city/country. Comparative analysis helps to detect the awareness and understand the culture and the society of the region in contrast with another regions (Martin, 2008), therefore, students were asked to submit the reports, where they were describing the linkage between the biological and cultural diversity and compared it with their own home city. In addition, students gave proposals about the preservation and sustainable utilization of the natural resources in ways to promote cultural development.

\section{Results}

From the reports it was clear that all students were able to learn about the biocultural diversity of the city and observe the challenges that are faced by the local people to preserve environmental stainability and creativity. $90 \%$ of the reports submitted by the students showed that nature which exist in the city is strongly related with the culture. And the loss of one part of nature, will bring to the loss in culture. Students reported the following aspects of the nature and the culture:

- Diverse nature provides all necessary materials for the craftsmen to preserve their local tradition and culture.

- Nature relates and affects the cultural diversity of the city.

- Nature is one of the strong points that could bring forward economic growth in the city.

- Kanazawa is a modern city, but still maintains local agricultural practice with traditional landscapes.

- Kanazawa City is rich in both traditional craft and modern art with unique handmade quality.

- Creativity of the shop owners who managed to transform an old building into a shop with modern interior design without jeopardising the traditional exterior design of the building.

- Strong linkages between the crafter, nature and the consumer is felt in the city.

- People created local culture by adapting to the local environment.

- Local traditional shops and crafts preserve the culture for generations while creating opportunities to keep on developing their products' quality and make innovations.

- Young people move back to the village because of their interest to care for their family's heritage, which brings hope to the community. They are inspired by the natural abundancy and are able to create the innovative ideas while preserving the traditional spirit inside the crafts. 
- Kanazawa City still have preserved very old traditional shops which dates back for more than 200 years. Supply needs a demand to remain, and this is how old shops still survive, because there is still the demand for such traditional supplies in the community.

- Strong encouragement from the local government to provides the support for the traditional crafts and shops.

Further students explained about the issues, which were observed during the fieldtrips. The biggest problem that was recorded was depopulation, aging, no young followers, lack of the awareness about problems within the communities. Next, it was observed about the high price for local and handmade crafts, which makes the products to be unaffordable for the local residents, and they are mainly sold to the consumers coming from outside. Also, the inability of the local shops to expand their business was another issue, as the natural resources which are need to create the crafts are coming from abroad with cheap price, and using the local materials requires higher cost. Finally the issues related to the pollution, invasive species, humans negative interaction with nature, and climate change were also recorded.

After the fieldworks and direct interviews with the locals, students provided the recommendation for the city that they found would be important for the future development and preservation of the local biocultural diversity. Most of the students provided the similar feedbacks and the list of the recommendations for the further actions are shown below:

- City must provide an opportunities to create small businesses and attract young people to live in rural area.

- Due to the limited transportation to the rural areas, less people can get the access to the local communities. Improve access and mobility to the rural areas, and promote volunteer activities to increase work force size.

- Branding of the local products. Traditional goods must be branded and start international export.

- Increase the demand for daily use in local goods among the citizens and consider reasonable pricing.

- Control tourism influx and negative human impacts on nature.

- Governmental involvement to support the economy of local products.

- Create the educational activities, to educate the young and local people in promoting the awareness about natural and cultural protection for sustainable utilization.

- Awareness transfer to younger generations about their culture, to preserve the demand and increase the supply.

- New educational approaches should be developed. "Young people consume what they are taught in school, at home, society and all the media. They consume what they are motivated to consume. However, because of the rapid modernization, and changes in society, the educational system is designed for students that don't exist anymore."

- Increase and promote creative tourism and eco-tourism.

- Ease the access to the creative ateliers of the craftsmen, so that consumers can buy new products, rather than buying standard souvenirs from the shops.

\section{Discussion}

According to the reports submitted by the students, it was clear that through the fieldworks students were able to directly learn about the culture and the creativity of the local people, and the awareness was increased about the present urban challenges. Student citation: "Field work provided, the opportunity to experience all stages of the consciousness and see how the culture is created form inside. We were able to be local customers, local producers, and just local citizens and feel all the atmosphere of the city by communicating and just "being" there together with nature and culture". However, only fieldwork experience were not sufficient to deepen the understanding about sustainable urban development. As biocultural diversity encompass the myriad of fields of sciences, so the methodological approach should be as integrated education, where students explore, identify, organize and incorporate the ideas and practise together, to develop the critical way of thinking and problem solving abilities. This time problem solving ideas were given according to the stories heard from the local people, without investigating the scientific backgrounds of the issues. Only comparative analysis and fieldworks were not sufficient to deepen the understanding about the linkage of the nature and the culture. Students, didn't provide any scientific approaches for the present issues of the biocultural diversity, and the ideas for the problem solving were given based on the generalized concept, without any research analysis.

To improve our methodological approach in our next studies we are going to develop approved survey instruments to record and analyse the data collected by students, and perform quantitative data analysis with second cohort research group to evaluate and confirm the outcomes of the field trips. 


\section{References}

Biodiversity strategy of Kanazawa City. (2016). Kanazawa City Homepage. Retrieved from http://www4.city.kanazawa.lg.jp/data/open/cnt/3/23326/6/gaiyou.pdf

Hafezi, S., Shobiri, S. M., Sarmadi, M. R., \& Ebadi, A. (2013). A Novel Conceptual Model of Environmental Communal Education: Content Analysis Based on Distance Education Approach. Turkish Online Journal of Distance Education-TOJDE, 14(1), 154-165. $\quad$ Retrieved from http://dergipark.ulakbim.gov.tr/tojde/article/view/5000102184/5000095283

Hospers, G. J. (2003). Creative cities: Breeding places in the knowledge economy. Knowledge, Technology \& Policy, 16(3), 143-162. Retrieved from https://link.springer.com/content/pdf/10.1007\%2Fs12130-003-1037-1.pdf

Hungerford, H. R., \& Volk, T. L. (1990). Changing learner behavior through environmental education. The Journal of Environmental Education, 21(3), 8-21. https://doi.org/10.1080/00958964.1990.10753743

International Congress of Ethnobiology. (2017). Retrieved from http://ethnobiology.net/global-coalition/declaration-of-belem/

KANAZAWA UNESCO Creative City 2013-2016 Report. Retrieved from http://www4.city.kanazawa.lg.jp/data/open/cnt/3/15014/1/KANAZAWA_2013_2016REPORT_ENG.pdf

Killermann, W. (1998). Research into biology teaching methods. Journal of Biological Education, 33, 4-9.

Maffi, L. (2007). Biocultural diversity and sustainability. The Sage handbook of environment and society, 267-277.

Martin, G. (2008). Restoring resilience. Resurgence, 205, 13-15. Retrieved from https://www.resurgence.org/magazine/article31-resilience-and-restoration.html

Özden, M. (2008). Environmental awareness and attitudes of student teachers: An empirical research. International Research in Geographical and Environmental Education, 17(1), 40-55. https://doi.org/10.2167/irgee227.0

Prokop, P., Tuncer, G., \& Kvasničák, R. (2007). Short-term effects of field programme on students knowledge and attitude toward biology: A Slovak experience. Journal of Science Education \& Technology, 16(3), 247-255. https://doi.org/10.1007/s10956-007-9044-8.

Ramadoss, A., \& Poyyamoli, G. (2011). Biodiversity conservation through environmental education for sustainable development-a case study from puducherry, India. International Electronic Journal of Environmental Education, $\quad$ l(2), 97-111. $\quad$ Retrieved from http://dergipark.ulakbim.gov.tr/iejeegreen/article/view/1087000019/1087000014

Sasaki, M. (2003). Kanazawa: a creative and sustainable city. Policy Science, 10(2), 17-30. Retrieved from http://www.ps.ritsumei.ac.jp/assoc/policy_science/102/102_02_sasaki.pdf

Udy Jr, S. H. (1973). Cross-cultural analysis: Methods and scope. Annual Review of Anthropology, 2(1), 253-270. https://doi.org/10.1146/annurev.an.02.100173.001345

Urban and Rural Areas. (1996). UN, New York United Nations publications (ST/ESA/SER.a/166), Sales No. E97.XIII.3.

WinklerPrins, A. M., \& De Souza, P. S. (2005). Surviving the city: urban home gardens and the economy of affection in the Brazilian Amazon. Journal of Latin American Geography, 4(1), 107-126. https://doi.org/10.1353/lag.2005.0033

\section{Copyrights}

Copyright for this article is retained by the author(s), with first publication rights granted to the journal.

This is an open-access article distributed under the terms and conditions of the Creative Commons Attribution license (http://creativecommons.org/licenses/by/4.0/). 